\title{
Big Five Personality Factors and Library Anxiety
}

\author{
Mohammad-Hossein Biglu1, Mostafa Ghavami2*, Sahar Dadashpour ${ }^{3}$ \\ ${ }^{1}$ Basic Science Department, Paramedical Faculty, Tabriz University of Medical Sciences, Tabriz, Iran \\ ${ }^{2}$ Radiology Department, Paramedical Faculty, Tabriz University of Medical Sciences, Tabriz, Iran \\ ${ }^{3}$ Iranian Center of Excellence in Health Management, Tabriz University of Medical Sciences, Tabriz, Iran \\ Email: biglu@tbzmed.ac.ir, *mostafa.ghavami@yahoo.com
}

Received 16 May 2016; accepted 16 August 2016; published 19 August 2016

Copyright (C) 2016 by authors and Scientific Research Publishing Inc.

This work is licensed under the Creative Commons Attribution International License (CC BY).

http://creativecommons.org/licenses/by/4.0/

(c) (i) Open Access

\begin{abstract}
Library anxiety is an unpleasant feeling that is experienced in a library location; it has behavioral, psychological, emotional and cognitive effect, which can be harmful for students' academic career. The purpose of current study was to investigate the relationship between Library anxiety and the Big Five personality factors (neuroticism, extraversion, openness-to-experience, agreeableness, and conscientiousness) using a multivariate approach among students in Ardabil university. The participants were students of Ardabil University of Medical Sciences of which a sample of 580 students was randomly selected. And the assessment methods were revised. The short form of NEO Inventory [1] and the library anxiety questionnaire [2] were used to gather the data. The results showed that Neuroticism increased library anxiety in students, and with increasing the level of education, library anxiety is reduced, whereas by increasing the semester the library anxiety of students increases.
\end{abstract}

\section{Keywords}

Library Anxiety, Big Five Personality Factors, Students

\section{Introduction}

The purpose of academic libraries is to support teaching and learning in colleges and universities. For students, academic libraries can serve as an extension of the classrooms by providing resources and services that enable students to achieve academic excellence. However, some students experience what the library literature describes as "library anxiety". Mellon described it as: “an uncomfortable feeling or emotional disposition that is

*Corresponding author. 
experienced when students are utilizing the library or contemplating its use” [3].

\subsection{Library Anxiety}

Library anxiety is described as "an uncomfortable feeling or emotional disposition, experienced in a library setting, which has cognitive, affective, physiological, and behavioral ramifications” [4]. Library anxiety is characterized by negative emotions-including tension, fear, feelings of uncertainty and helplessness, negative selfdefeating thoughts, and mental disorganization - that are experienced in the library setting [4]. It is a kind of psychological barrier that hinders users' access to information, and has been described in the broader term, information barriers [5] [6]. A common phenomenon occurring among a majority of students [3] [4], library anxiety is an important issue. Librarians have noticed for decades that some students experience high levels of apprehension about using an academic library [4], but only in the last 3 decades the formal systematic studies been conducted on the nature, characteristics and consequences of this phenomenon. Library anxiety has an incapacitating effect on a user's ability to perform library information-seeking tasks and research performance in general [4].

Important step in the field of research in the library anxiety were taken by Bostick (1992). He has identified five general introduction of library anxiety as "barriers with staff”, "affective barriers", "comfort with the library”, "knowledge of the library”, “mechanical barriers”. With this classification and criteria for library anxiety to assess quantitatively, he could take an important step forward in terms of research in this area; because studies in the past have been qualitative [7]. Barriers with staff is due to students' perception that librarians and other library staff are not receptive and create fear in patrons, and also are very busy and do not have the opportunity to help clients. Students with these perceptions show high levels of library anxiety. Some of the reasons of students for the librarians are receptive that can be as follow: Unfriendly librarians, some bad experiences in the past, students tend not to look stupid, inability of students to communicate with the print media, bad communication of librarian with curious and unfamiliar clients, inadequate library tendency program, inability of librarian in response to questions referred to the cause of not trying to train and increase their information and ultimately, fear of the use of new technology [8]. Affective barriers are rooted in students' inadequacy of using library. Feeling comfortable in the library is related with the fact that how much the library is safe, welcoming, and non-scary environment for students. Library knowledge concerning with, how students' feels familiar with the library. Finally, mechanical barriers refer to the feelings associated with customer confidence to equipment for the library. The studies showed that those who have difficulty in using the equipment, experience more anxiety [9].

\subsection{The Big Five Personality Factors}

The Big Five personality factors refer to a hierarchical organization of personality traits into five basic dimensions: (N) Neuroticism, (E) Extraversion, (O) Openness to Experience, (A) Agreeableness, and (C) Conscientiousness [1] [10]. Neuroticism is the tendency to be sensitive, emotional, and to be prone to experience negative emotions. Extraversion is characterized by being outgoing and active, along with a tendency to seek and to prefer the company of others. Openness to Experience refers to an inclination for a diverse and broad range of new experiences. Agreeableness is the tendency to be compassionate, good natured, and eager to cooperate and avoid conflict. Lastly, Conscientiousness refers to a tendency to exhibit goal-directed behavior, such as persistence, organization, and motivation. Since its conceptualization, a number of studies have investigated the role of the Big Five personality factors in predicting academic achievement. In general, Neuroticism and Extraversion tend to be negatively correlated whereas Openness to Experience, Agreeableness, and Conscientiousness tend to be positively correlated with various indicators of academic achievement such as final-year projects and examinations [11]-[14]. More relevant to the current study, Furnham and Chamorro-Premuzic [15] found Extraversion and Openness to Experience to be negatively correlated and Conscientiousness to be positively correlated with statistics examination grades.

Given that both statistics anxiety and the Big Five personality factors are related to academic achievement, it is likely that a direct relationship exists between these two constructs. However, little or no research has investigated the relationship between statistics anxiety and the Big Five personality factors. Knowledge of the personality traits of students who experience high statistics anxiety allows statistics instructors to identify and target high-risk of individuals for intervention. Additionally, a relationship between a trait-like construct (Big Five 
personality factors) and a state-like construct (statistics anxiety) furthers understanding of both constructs. In particular, the relationship could shed light on the nature and antecedents of statistics anxiety, which could assist in the development of interventions.

Personality traits, as an organized set and a unit with relatively stable characteristics in persons, that distinguished an individual from other individuals, can affect the anxiety [16].

Costa and McCraestated five great personality or five "Super Traits" as follows: Neuroticism (N), Extroversion (E), Openness (O), Agreeableness (A), and Conscientiousness (C). Neuroticism is called to a tendency for people to experience negative emotions such as anxiety, depression and anger. Extroversion is called to the willingness of the person to be happy, sociable and energetic. Openness is relevant to the willingness of people to non-traditional and imaginative. Agreeableness is the intention to trusting, and generous donors, and finally, the Conscientiousness is the person to be trustworthy, diligent and regular points. According to Witt [17], the personality can be used to predict the behavior and job performances. Khosravi and Bigdeli [18], in their study revealed positive relationship between exam-anxiety and neurosis; however, there is no significant relationship between exam-anxiety and introversion/extraversion. Among the studied personality traits, neuroticism could be predictive variable of exam-anxiety. Meanwhile, a significant difference between boys and girls has not been found in personality traits. The results of Rahimi [19] and Wine's [20] studies also showed that there is a negative correlation between anxiety and extroversion. This means that introversion is positively correlated with anxiety. Because the relationship between personality traits with general anxiety is confirmed, however, few studies have been conducted to study the relationship between personality and library anxiety. This study aimed to investigate the Relationships between "Personality traits and demographic characteristics" and library-anxiety among students of Medical Sciences University of Ardabil.

\section{Methods and Materials}

\subsection{Participants}

A total number of 580 students (63\% female, 37\% male) were selected based on convenience of location and availability to the population from five Schools (Public Health, Midwifery, Medicine, pharmaceuticals and dentistry) with the degree of separation in 17 fields of study among Medical Sciences University of Ardabil. The study was carried out between January and June 2016.

\subsection{Instruments}

In order to measure the variables, the following tools were used:

Bostick library anxiety scale [21]: Standardized questionnaire was Bostick research project as library anxiety in United States of America (1992), the reliability and validity of which has already been approved by researchers at the universities of Iran. Reliability was assessed using Cronbach's alpha and was 0.69. Bostick library anxiety scale is in the form of 39 questions related to the five library anxiety factors (factors resulting from the interaction with librarians, affective factors, discomfort in the library, lack of skills and education library, mechanical factors).

NEO Personality Inventory: NEO Personality Inventory was made by Costa and McCrae in 1985. This questionnaire measures five dimensions of personality: introversion, extroversion, openness, agreeableness and conscientiousness. This questionnaire is one of the most famous scales to assess the personality traits, the reliability and validity of which has already been done in Iran. After collecting research data using multiple regression analysis was conducted in SPSS software.

To guarantee the privacy of participants' information all questionnaires were anonymous.

\section{Results}

All results were analyzed using SPSS version 16.0 with the alpha level set at 0.05 .

Table 1 shows the mean, standard deviation, minimum and maximum and sub-criteria of library anxiety among students.

To examine the hypotheses, multiple regression was used to test the results of which are presented in the following tables.

In accordance with the information contained in Table 2 based on multiple regression equation, to determine 
Table 1. Variable descriptive indicators and standards of library anxiety among students.

\begin{tabular}{cccc}
\hline Sub-criteria & Median of test & Mean & Standard deviation \\
\hline Barriers with staff & 30 & 28.88 & 0.26 \\
Affective barriers & 18 & 33.61 & 0.29 \\
Comfort with the library & 33 & 18.72 & 0.14 \\
Knowledge of the library & 21 & 12.05 & 0.1 \\
Mechanical barriers & 3 & 6.06 & 0.09 \\
Total score & 105 & 99.343 & 0.61 \\
\hline
\end{tabular}

Table 2. Multiple regression analysis to examine the impact of personality traits and demographic on library anxiety.

\begin{tabular}{cccc}
\hline R & Modified $\mathrm{R}^{2}$ & Watson & Level of significance \\
\hline 0.386 & 0.144 & 0.966 & 0.000 \\
Library anxiety & $\mathrm{B} \pm \mathrm{SE}$ & $\begin{array}{c}\text { Standardized coefficient } \\
\text { the beta }\end{array}$ & Level of significance \\
Constant & $79.81 \pm 3.28$ & - & 0.00 \\
Neuroticism & $0.57 \pm 0.07$ & 0.356 & 0.00 \\
Semester & $-2.5 \pm 1.22$ & 0.086 & 0.041 \\
Level & $1.06 \pm 0.52$ & -0.086 & 0.042 \\
\hline
\end{tabular}

the library anxiety among students in terms of demographic characteristics, including environment, gender, educational level, marital status, exotic, age, average, and in terms of personality, including: Neuroticism, Openness, Agreeableness, Introversion, Extroversion, and Conscientiousness, it was observed that of Personality characteristics, only neuroticism and demographic characteristics, semesters and level remained in the model, the multiple correlation between them is $(\mathrm{R}=0.386)$ and a significant level is $\mathrm{p}<0.01$, there is a significant linear correlation between predictive criteria. The $\mathrm{R}_{\text {adj }}^{2}=0.144$ shows that $14.4 \%$ of the variance of library anxiety is predictable through neurosis, semester and academic levels; So that neurosis with a beta value of 0.356 has the largest role in estimation of library anxiety.

Of the demographic characteristics, level of education and semester involved in estimating library anxiety. So that education with a beta value of -0.086 , and the semester with a beta value of 0.086 are involved in the estimation of the library anxiety. Therefore, it can be concluded that by increasing the level of education, library anxiety is reduced and with increasing terms of educational, library anxiety among students increases.

In accordance with the information contained in Table 3 based on multiple regression equation, to determine the obstacles related to staff as one of the criteria of library anxiety among students In terms of personality and demographic characteristics, it was observed that the of Personality characteristics neuroticism, openness and agreeableness and of demographic characteristics, semesters and level remained in the model, the multiple correlation between them is $(R=0.507)$ and a significant level is $p<0.01$, there is a significant linear correlation between predictive criteria. The $\mathrm{R}_{\text {adj }}^{2}=0.25$ shows that $25 \%$ of the variance of barriers with staff as one of the criteria of library anxiety among students is predictable through neurosis, openness, agreeableness, gender and academic levels; Of the demographic characteristics, level of education and semester involved in estimating library anxiety. So that neurosis with a beta value of 0.442 has the largest role in the estimation of barriers with staff, and the agreeableness with a beta value of -0.125 , the openness with a beta value of -0.078 , the level with a beta value of -0.115 and gender with a beta value of -0.103 are involved in the estimation of the barriers with staff as one of the criteria of library anxiety among students. Therefore, it can be concluded that by increasing the neurosis barriers with staff as one of the criteria of library anxiety increases and openness and agreeableness reduces it and with increasing educational terms, library anxiety among students' increases. 
Table 3. Multiple regression analysis to examine the impact of personality traits and demographic on barriers with staff.

\begin{tabular}{cccc}
\hline R & Modified $\mathrm{R}^{2}$ & Watson & Level of significance \\
\hline 0.507 & 0.25 & 0.818 & 0.000 \\
Barriers with staff & $\mathrm{B} \pm \mathrm{SE}$ & $\begin{array}{c}\text { Standardized coefficient } \\
\text { the beta }\end{array}$ & Level of significance \\
Constant & $31.1 \pm 2.98$ & - & 0.000 \\
Neuroticism & $0.29 \pm 0.03$ & 0.422 & 0.000 \\
Openness & $-0.12 \pm 0.04$ & -0.0788 & 0.004 \\
Sex & $-0.09 \pm 0.05$ & -0.103 & 0.048 \\
Level of education & $-1.44 \pm 0.05$ & -0.115 & 0.004 \\
Agreeableness & 0.010 & -0.125 & 0.010 \\
\hline
\end{tabular}

In accordance with the information contained in Table 4 based on multiple regression equation, to determine the affective barriers as one of the criteria of library anxiety among students in terms of personality and demographic characteristics, it was observed that of Personality characteristics only neuroticism, and of demographic only semester remained in the model, the multiple correlation between them is $(\mathrm{R}=0.259)$ and a significant level is $\mathrm{p}<0.01$, there is a significant linear correlation between predictive criteria. The $\mathrm{R}_{\text {adj }}^{2}=0.065$ shows that $6.5 \%$ of the variance of affective barriers as one of the criteria of library anxiety among students is predictable through neurosis and semester. So that neurosis with a beta value of 0.241 and the semester with a beta value of -0.088 are involved in the estimation of the emotional factors as one of the criteria of library anxiety among students. Therefore, it can be concluded that by increasing the neurosis affective barriers as one of the criteria of library anxiety increases and as the semesters increase affective barriers among students' increase.

In accordance with the information contained in Table 5 based on multiple regression equation, to determine comfort with the library as one of the criteria of library anxiety among students In terms of personality and demographic characteristics, it was observed that the of Personality characteristics neuroticism and agreeableness and of demographic characteristics age and educational level remained in the model, the multiple correlation between them is $(R=0.512)$ and a significant level is $\mathrm{p}<0.01$, there is a significant linear correlation between predictive criteria. The $\mathrm{R}_{\text {adj }}^{2}=0.262$ shows that $26.2 \%$ of the variance of comfort with the library as one of the criteria of library anxiety among students is predictable through neurosis, agreeableness, age and educational level. So that neurosis with a beta value of 0.171 , agreeableness, age with a beta value of -0.171 and educational level with a beta value of -0.095 are involved in the estimation of the comfort with the library as one of the criteria of library anxiety among students. Therefore, it can be concluded that by increasing the neurosis, comfort with the library as one of the criteria of library anxiety increases and as agreeableness reduces it, also as age increases the comfort with the library as one of the criteria of library anxiety increases and educational level reduces it.

In accordance with the information contained in Table 6 based on multiple regression equation, to determine the knowledge of the library as one of the criteria of library anxiety among students In terms of personality and demographic characteristics, it was observed that the of Personality characteristics only Conscientiousness, and of demographic only Level of education remained in the model, the multiple correlation between them is ( $\mathrm{R}=$ 0.434 ) and a significant level is $\mathrm{p}<0.01$, there is a significant linear correlation between predictive criteria. The $\mathrm{R}_{\text {adj }}^{2}=0.185$ shows that $18.5 \%$ of the variance of knowledge of the library as one of the criteria of library anxiety among students is predictable through Conscientiousness and Level of education. So that Conscientiousness with a beta value of 0.422 and the Level of education with a beta value of -0.123 are involved in the estimation of the knowledge of the library as one of the criteria of library anxiety among students. Therefore, it can be concluded that by increasing the Conscientiousness knowledge of the library as one of the criteria of library anxiety increases and as the level of education increase knowledge of the library among students' reduces.

In accordance with the information contained in Table 7 based on multiple regression equation, to determine the mechanical barriers as one of the criteria of library anxiety among students. In terms of personality and 
Table 4. Multiple regression analysis to examine the impact of personality traits and demographic on affective barriers.

\begin{tabular}{cccc}
\hline $\mathrm{R}$ & Modified $\mathrm{R}^{2}$ & Watson & Level of significance \\
\hline 0.259 & 0.063 & 1.065 & 0.000 \\
Affective barriers & $\mathrm{B} \pm \mathrm{SE}$ & $\begin{array}{c}\text { Standardized coefficient } \\
\text { the beta }\end{array}$ & $\begin{array}{c}\text { Level of significance } \\
\text { Constant }\end{array}$ \\
Neuroticism & $25.84 \pm 1.33$ & - & 0.00 \\
Semester & $0.18 \pm 0.03$ & 0.241 & 0.00 \\
\hline
\end{tabular}

Table 5. Multiple regression analysis to examine the impact of personality traits and demographic on comfort with the library.

\begin{tabular}{cccc}
\hline $\mathrm{R}$ & Modified $\mathrm{R}^{2}$ & Watson & Level of significance \\
\hline 0.512 & 0.262 & 0.061 & 1.157 \\
Comfort with the library & $\mathrm{B} \pm \mathrm{SE}$ & $\begin{array}{c}\text { Standardized coefficient } \\
\text { the beta }\end{array}$ & Level of significance \\
Constant & $18.14 \pm 1.25$ & - & 0.00 \\
Age & $0.06 \pm 0.02$ & 0.154 & 0.00 \\
Neuroticism & $0.057 \pm 0.217$ & 0.0171 & 0.001 \\
Educational level & $-0.63 \pm 0.3$ & -0.095 & 0.036 \\
Agreeableness & $-0.05 \pm 0.02$ & -0.095 & 0.048 \\
\hline
\end{tabular}

Table 6. Multiple regression analysis to examine the impact of personality traits and demographic on the knowledge of the library.

\begin{tabular}{cccc}
\hline $\mathrm{R}$ & Modified $\mathrm{R}^{2}$ & Watson & Level of significance \\
\hline 0.434 & 0.185 & 1.09 & 0.00 \\
Knowledge of the library & $\mathrm{B} \pm \mathrm{SE}$ & $\begin{array}{c}\text { Standardized coefficient } \\
\text { the beta }\end{array}$ & $\begin{array}{c}\text { Level of significance } \\
\text { Constant }\end{array}$ \\
Conscientiousness & $0.13 \pm 0.04 \pm 0.62$ & - & 0.00 \\
Level of education & $-0.06 \pm 0.02$ & 0.422 & 0.00 \\
\hline
\end{tabular}

Table 7. Multiple regression analysis to examine the impact of personality traits and demographic on mechanical barriers.

\begin{tabular}{cccc}
\hline $\mathrm{R}$ & Modified $\mathrm{R}^{2}$ & Watson & Level of significance \\
\hline 0.512 & 0.262 & 0.061 & 1.157 \\
Mechanical barriers & $\mathrm{B} \pm \mathrm{SE}$ & $\begin{array}{c}\text { Standardized coefficient } \\
\text { the beta }\end{array}$ & Level of significance \\
Constant & $6.47 \pm 0.87$ & - & 0.00 \\
Neuroticism & $0.03 \pm 0.01$ & 0.137 & 0.05 \\
Conscientiousness & $-0.03 \pm 0.01$ & -0.123 & 0.011 \\
\hline
\end{tabular}


demographic characteristics, it was observed that the of Personality characteristics neuroticism and conscientiousness, and of none of demographic characteristics remained in the model, the multiple correlation between them is $(R=0.217)$ and a significant level is $\mathrm{p}<0.01$, there is a significant linear correlation between predictive criteria. The $\mathrm{R}_{\mathrm{adj}}^{2}=0.043$ shows that $4.3 \%$ of the variance of mechanical barriers as one of the criteria of library anxiety among students is predictable through neuroticism and conscientiousness. So that neuroticism with a beta value of 0.137 and the conscientiousness with a beta value of -0.123 are involved in the estimation of the mechanical barriers as one of the criteria of library anxiety among students. Therefore, it can be concluded that by increasing the neuroticism, mechanical barriers as one of the criteria of library anxiety increases.

\section{Discussion and Conclusion}

The results showed that library-anxiety of students in all subscales are in the middle to low level, and components of library anxiety, barriers with staff, affective barriers and knowledge of the library are in the mechanical and affective barriers which are in lower-middle upper-middle-class, that shows the main library anxiety of medical sciences students of Ardabil are related to emotional and mechanical barriers. Affective barriers are rooted in students' feelings of inadequacy in the use of the library, and mechanical barriers are related to students' feelings of trust to equipment of the library. It seems that those who have difficulty in using this equipment have experienced more anxiety. Jiaoand Onwuegbuzie [22] in a study investigated the factors related to the five library anxiety among a sample of 522 students from two universities. They concluded that the use of library facilities for some clients brings a great deal of anxiety. And the researchers suggest that to reduce this anxiety, librarians and library staff should monitor students' use of the equipment, and to help any student who is having trouble. Jiaoand Onwuegbuzie [23] also concluded that mechanical barriers are main cause of high levels of anxiety library. It seems that the mechanical barriers are recognized as problematic factors in the increasing of library anxiety in international students. The probability reason was that, the majority of these students were from the countries with Lowe level of new technologies. The findings of this study showed that among personality characteristics, neuroticism makes to increase the library anxiety in students, which is in agreement with the results of the previous studies [24], Joyce and Meredith [25], Rahimi [19]. It seems that the neurotic and anxiety students, has more experience library anxiety and relate their failures to internal factors such as academic problems. Neurotic people are isolated and isolationist, and have tendency to feel deficiency (inferiority) in them is high, and the risk for anxiety, depression and obsession are more them. People with high neuroticism, in parts of the brain that the sympathetic branch of the autonomic nervous system controls, show more activity [26]. Other results showed that with increasing level of education, anxiety reduces and with increasing educational semesters, library anxiety among students increases. Perhaps one of the reasons why higher education in library anxiety is low, is that in higher education, particularly in MA and PhD students, fear from librarians and other library staff reduced, feelings of inadequacy in use of the library reduces, the students' familiarity with library increase and students master in using the equipment of library increase and therefore anxiety reduces.

With increasing semesters, library anxiety in students increase. Reasons can be tasks which become heavier, fear of job prospects, need to study English sources and performing complex searches on these resources-especially in electronic resources - and probably a sense of perfectionism which exists among the students of this level, and some general anxieties, which caused a significant increase in this group's library anxiety. A similar study Jiao and Onwuegbuzie [21] also show people that their native language is not English and who have relatively large and difficult course curriculum, have high anxiety library. In other study followed by Jiao study Jiao and Onwuegbuzie [9] it has been shown that perfectionist experience more library anxiety than of their non-perfectionist peers. In addition, the interesting discussion that has been studied in some research abroad, is research and statistical anxiety caused by students' difficult research projects and theses and this problem in higher students due to the need to offer such plans and the subsequent increasing in their need for information in the library and using them in increases their library anxiety.

The overall result is that of the library anxiety has limitation of time and space, and symptoms appear only when the students are in the library or consider to visit the library, so it is a present time-based anxiety more than a type of anxiety on the based to mode and characterization. Characteristics anxiety can be defined as a permanent and relatively stable personality trait. This means that characteristics anxiety is not limited to time and place. In other words, situational anxiety is considered as a temporary situation that will change based on time. Situational anxiety is specific to time and place. Students with high characteristics anxiety, trait anxiety are 
more afflicted to situational than those who have low characteristics anxiety. The reason is that these students tend to interpret more threatening situations. Situational Anxiety has the opposite effect on learning and progress [27].

The results of the study indicated that the high levels of emotions and mechanical barriers are the main obstacles for students in the university libraries. Therefore, providing the training courses for students and employing the behavioral science consultants in the libraries would promote the suitable use of library materials by students in the university libraries.

\section{Acknowledgements}

We would like to thanks all people who helped us during the study.

\section{Conflict of Interest}

The authors declare that there is no conflict of interests.

\section{Ethical Approve}

The study was approved by the ethics committee of Tabriz University of Medical Sciences.

\section{References}

[1] Costa, P.T.J. and McCrae, R.R. (1992) Revised NEO Personality Inventory (NEO-PI-R) and NEO Five-Factor Inventory (NEO-FFI) Professional Manual. Psychological Assessment Resources, Odessa, FL.

[2] Bostick, S.L. (1992) The Development and Validation of the Library Anxiety Scale: UMI.

[3] Mellon, C.A. (1986) Library Anxiety: A Grounded Theory and Its Development. College \& Research Libraries, 47, 160-165. http://dx.doi.org/10.5860/crl_47_02_160

[4] Onwuegbuzie, A.J., Jiao, Q.G. and Bostick, S.L. (2004) Library Anxiety: Theory, Research, and Applications. Scarecrow Press, Lanham, MD, and Oxford:

[5] Świgoń, M. (2006) Bariery informacyjne: Podstawy teoretyczne i próba badań w środowisku naukowym. [Information Barriers: Theory and an Attempt to Study in the Scientific Community]. Stowarzyszenie Bibliotekarzy Polskich, Uniwersytet Warmińsko-Mazurski w Olsztynie, Warsaw.

[6] Świgoń, M. (2010) Information Barriers in Libraries-Types, Typologies and Polishempirical Studies. Paper Presented at the 2nd International Conference Qualitative and Quantitative Methods in Libraries, Chania, Crete.

[7] Cleveland, A. (2004) Library Anxiety: A Decade of Empirical Research. Library Review, 53, 177-185. http://dx.doi.org/10.1108/00242530410526583

[8] Patrick, D.F. (2004) Student Anxiety in library Use (Letter to the Editor). ACTEA Librarians Enews.

[9] Jiao, Q.G., and Onwuegbuzie, A.J. (1998) Perfectionism and Library Anxiety among Graduate Students. Journal of Academic Librarianship, 24, 365-371. http://dx.doi.org/10.1016/S0099-1333(98)90073-8

[10] Goldberg, L.R., Johnson, J.A., Eber, H.W., Hogan, R., Ashton, M.C., Cloninger, C.R. and Gough, H.G. (2006) The International Personality Item Pool and the Future of Public-Domain Personality Measures. Journal of Research in Personality, 40, 84-96. http://dx.doi.org/10.1016/j.jrp.2005.08.007

[11] Chamorro-Premuzic, T. and Furnham, A. (2003) Personality Traits and Academic Examination Performance. European Journal of Personality, 17, 237-250. http://dx.doi.org/10.1002/per.473

[12] Chamorro-Premuzic, T. and Furnham, A. (2003) Personality Predicts Academic Performance: Evidence from Two Longitudinal University Samples. Journal of Research in Personality, 37, 319-338. http://dx.doi.org/10.1016/S0092-6566(02)00578-0

[13] Komarraju, M., Karau, S.J. and Schmeck, R.R. (2009) Role of the Big Five Personality Traits in Predicting College Students’ Academic Motivation and Achievement. Learning and Individual Differences, 19, 47-52. http://dx.doi.org/10.1016/j.lindif.2008.07.001

[14] Lounsbury, J.W., Sundstrom, E., Loveland, J.M. and Gibson, L.W. (2003) Intelligence, “Big Five” Personality Traits, and Work Drive as Predictors of Course Grade. Personality and Individual Differences, 35, 1231-1239. http://dx.doi.org/10.1016/S0191-8869(02)00330-6

[15] Furnham, A. and Chamorro-Premuzic, T. (2004) Personality and Intelligence as Predictors of Statistics Examination Grades. Personality and Individual Differences, 37, 943-955. http://dx.doi.org/10.1016/j.paid.2003.10.016 
[16] Shamloo, S. (2003) Schools and Theories of Personality Psychology. Roshd Press, Tehran.

[17] Michel, W.L.A., Kakmer, K., Dawns, C. and Suzane, Z. (2002) Interactive Effects of Personality and Organizational Politics on Contextual Performance. Journal of Organizational Behavior, 23, 189-201.

[18] Khosravi, M. and Bigdeli, I. (2008) Relationships between Characteristics of Personality and Exam Anxiety among Students. Journal of Behavioral Sciences, 2, 13-24.

[19] Rahimi, F. (2000) Investigate the Causes of Anxiety of High School and Pre-University Students (Girl and Boy) in the Academic Year 2000-2001 City of Shahreza. Karbord Research Design, Behavioral Sciences Research Center.

[20] Wine, J. (1980) Cognition Attention Theory of Test Anxiety. University of Waterloo Press, Waterloo.

[21] Bostick, S.L. (1992) The Development and Validation of the Library Anxiety Scale. Ph.D. Dissertation, Wayne State University, Detroit.

[22] Jiao, Q.G. and Onwuegbuzie, A.J. (1997) Prevalence and Reasons for University Library Usage. Library Review, 46, 411-420. http://dx.doi.org/10.1108/00242539710178416

[23] Jiao, Q.G. and Onwuegbuzie, A.J. (1999) Is Library Anxiety Important? Library Review, 48, 278-282. http://dx.doi.org/10.1108/00242539910283732

[24] Dadsetan, P. (1997) Assessment and Treatment of Exam Anxiety. Journal of Psychology, 1, 31-60.

[25] Joyce, E.B. and Meredith, A.V. (2007) Personality and Emotional Performance: Extra Version, Neuroticism, and SelfMonitoring. Journal of Occupational Health Psychology, 12, 177-192. http://dx.doi.org/10.1037/1076-8998.12.2.177

[26] Siasi, A. (2000) Theories of Personality. University of Tehran Press, Tehran.

[27] Spielberger, C.D. and Anton. W.D. (2007) The Nature and Treatment of Test Anxiety. In: Zuekerman, M. and Spielberger, C.D., Eds., Emotions and Anxiety: New Concept Method and Applications, Wiley, New York, 317-345.

\section{Submit or recommend next manuscript to SCIRP and we will provide best service for you:}

Accepting pre-submission inquiries through Email, Facebook, LinkedIn, Twitter, etc.

A wide selection of journals (inclusive of 9 subjects, more than 200 journals)

Providing 24-hour high-quality service

User-friendly online submission system

Fair and swift peer-review system

Efficient typesetting and proofreading procedure

Display of the result of downloads and visits, as well as the number of cited articles

Maximum dissemination of your research work

Submit your manuscript at: http://papersubmission.scirp.org/ 